\title{
Safety and Efficacy of Using Tranexamic Acid at the Beginning of Robotic-Assisted Radical Prostatectomy in a Double-Blind Prospective Randomized Pilot Study
}

\author{
Michal Balík ${ }^{1}$, Josef Košina ${ }^{1}$, Petr Hušek ${ }^{1}$, Miloš Brodák ${ }^{1}$, Filip Čečka ${ }^{2, *}$
}

\begin{abstract}
Background: The prophylactic administration of tranexamic acid has been shown to be appropriate for procedures with a high risk of perioperative bleeding in cardiac surgery and orthopaedics. In urology the ambiguous results have been reported. Our goal was to evaluate the effect of tranexamic acid administration in robotic-assisted radical prostatectomy (RARP). A pilot, prospective, double-blind, randomized study was conducted to evaluate this effect.

Methods: The study included 100 patients who received RARP in the period from April 2017 to January 2018. The patients were randomly assigned to study and control groups of 50 patients each.

Results: The median follow-up was 6 months. Lower haemoglobin level drop weighted for gram of operated prostate was observed in the study group when treating the dorsal vein complex (DVC) at the beginning of the procedure $(p=0.004$ after 3 hours and $p<0.001$ after 24 hours). There was no evidence of any serious side effect of tranexamic acid.

Conclusion: We demonstrated the safety of tranexamic acid at RARP. In addition, we showed that administration of tranexamic acid at the beginning of RARP significantly reduces the decrease in haemoglobin after the procedure when treating the DVC at the beginning of the procedure.
\end{abstract}

\section{KEYWORDS}

tranexamic acid; robotic-assisted radical prostatectomy; prostate carcinoma

AUTHOR AFFILIATIONS

${ }^{1}$ Department of Urology, Faculty of Medicine and University Hospital Hradec Králové, Czech Republic

${ }^{2}$ Department of Surgery, Faculty of Medicine and University Hospital Hradec Králové, Czech Republic

* Corresponding author: Department of Surgery, Faculty of Medicine and University Hospital Hradec Králové, Sokolská 581, Hradec Králové, Czech Republic; e-mail: filip.cecka@fnhk.cz

Received: 24 May 2020

Accepted: 29 September 2020

Published online: 22 December 2020

Acta Medica (Hradec Králové) 2020; 63(4): 176-182

https://doi.org/10.14712/18059694.2020.60

(c) 2020 The Authors. This is an open-access article distributed under the terms of the Creative Commons Attribution License (http://creativecommons.org/licenses/by/4.0), which permits unrestricted use, distribution, and reproduction in any medium, provided the original author and source are credited. 


\section{INTRODUCTION}

Prostate adenocarcinoma is the most common malignancy in men. The incidence increases over time and with patient age. Prostate adenocarcinoma is the second most common cause of death due to malignancy in men, after lung cancer. In patients with moderate- and low-risk prostate cancer and life expectancy more than 10 years, the method of choice is radical prostatectomy or radiotherapy (1-3).

In recent years, we have seen a general tendency towards minimally invasive surgical procedures. In the treatment of localized prostate cancer, laparoscopic and robotic-assisted radical prostatectomy (RARP) have become the gold standard. Despite tremendous development in the technology and technique of robotic-assisted radical prostatectomy over more than 25 years, we still need to look for ways to improve oncological and functional outcomes (4-8).

We can assume that lower perioperative blood loss will lead to a better view in the operating field and improve the outcomes. Decreasing postoperative blood loss may lead to faster recovery after the procedure (9). Concerns have been raised about the possible relationship between the administration of blood derivatives and an increased risk of relapse of malignancy and tumour-specific mortality $(10,11)$.

Tranexamic acid is an antifibrinolytic used to relieve bleeding. The mechanism of action lies in binding to plasma free plasminogen with higher affinity than tissue plasminogen activator. It prevents its conversion to plasmin, which is responsible for the degradation of fibrin polymers. The result is greater stability of the fibrin clot at the site of bleeding and, therefore, lower blood loss (12-14). Use of tranexamic acid during or after the operation does not improve results, unlike administration prior to surgery. A biological explanation is that tranexamic acid may bind plasminogen in the early phase of the fibrinolytic cascade, after the beginning of the procedure, reducing tissue plasminogen activator activity up to $80 \%$ (15).

In urological surgery, increased conversion of plasminogen to plasmin should occur, both by washing the tissue plasminogen activator from the destroyed tissue and by urokinase present in the urine (16). Only a few studies have been published to date on the use of tranexamic acid in transurethral prostate resection, open radical prostatectomy, and open radical cystectomy. The first paper did not confirm the positive effect in terms of reduced perioperative and postoperative blood loss in prostate transurethral resection (17). Increasing evidence of the beneficial use of tranexamic acid in cardiac surgery, neurosurgery, traumatology, and orthopaedics has led to the renewal of this idea (18-20).

In urology, the results are not clear, as they differ in various urological procedures, e.g. endoscopic transurethral resections with negative results (21) to positive results in other procedures (22-25). Recent meta-analysis confirmed these positive results for cancer patients, in general (26).

Our goal was to investigate the effect of tranexamic acid on perioperative and postoperative blood loss, procedure duration, and reduction of the risk of positive surgical margin in RARP. A secondary goal was to monitor adverse events, such as acute myocardial infarction, stroke, generalized convulsions, and thromboembolic events.

\section{MATERIAL AND METHODS}

This pilot, prospective, randomized, double-blind, and placebo-controlled study was approved by the Ethics Committee in University Hospital in Hradec Králové (201704S06P). Between April 2017 and January 2018, 144 RARP were performed in our department.

We acquired patients scheduled for RARP without pelvic lymphadenectomy who provided informed consent. We primarily excluded patients who did not sign informed consent $(n=18)$ or had pelvic lymphadenectomy planned $(n=15)$. We assumed that pelvic lymphadenectomy would distort the results by prolonging the procedure time and increasing the volume of fluids in the suction and drain after surgery. Another exclusion criterion was coagulation disorder, congenital (e.g., Leiden mutation or thrombophilia) or iatrogenic due to the chronic use of antiaggregants or anticoagulants. We also excluded patients who had a thromboembolic, cerebral, or acute coronary event 6 months prior to prostatectomy $(n=9)$. None of the patients had a proven allergic reaction to tranexamic acid, which was the last exclusion criterion. A total of $100 \mathrm{pa}-$ tients were finally analyzed in the study.

After enrolment, each patient was assigned a unique number from 0 to 100 generated by an independent worker at www.randomizer.org prior to the study. The first 50 numbers generated represented patients assigned to the tranexamic acid group. The remaining numbers were assigned to the control group. The group assignment information was placed in a sealed envelope marked with the study number.

On the day of the procedure, an assigned nurse prepared an infusion set according to the information in the sealed envelope with the patient's study number. For patients in the treatment group, $1.5 \mathrm{~g}$ of tranexamic acid was added to $100 \mathrm{ml}$ of physiological saline and was given within 5 minutes after the robotic system was docked.

The therapeutic concentration of tranexamic acid in plasma ranges from $5 \mathrm{mg} / \mathrm{kg}$ to $10 \mathrm{mg} / \mathrm{kg}$. After an intravenous dose of $10 \mathrm{mg} / \mathrm{kg}$, plasma concentration was maintained for 3 hours, but in orthopaedics, it was proved to be inadequate $(27,28)$. The $20 \mathrm{mg} / \mathrm{kg}$ dose maintains a therapeutic level for 8 hours but increases the risk of a thromboembolic event (19). Based on the above-mentioned literature, we decided to administer a single dose of $1.5 \mathrm{~g}$ tranexamic acid to all patients in the treatment group, corresponding to $10-20 \mathrm{mg} / \mathrm{kg}$.

All patients underwent RARP without pelvic lymphadenectomy. A total of four surgeons performed the procedure using almost the same technique. The only difference was treatment of the dorsal vein complex (DVC). One surgeon sutured the DVC at the beginning of the procedure with two rounds of resorbable monofilament suture $(\mathrm{n}=38)$. Other surgeons treated the complex with several rounds of barbed suture after completing prostatectomy $(n=62)$. To accelerate the return of continence, a modified 
Tab. 1 Cohort parameters (TA - tranexamic acid group).

\begin{tabular}{|l|l|l|l|l|l|l|l|l|}
\hline & \multicolumn{3}{|l}{ Age (years) } & \multicolumn{2}{l|}{ BMI } & \multicolumn{2}{l|}{ iPSA (ng/ml) } & \multicolumn{3}{l|}{ Specimen weight (g) } \\
\cline { 2 - 9 } & TA & Placebo & TA & Placebo & TA & Placebo & TA & Placebo \\
\hline Average & 64.3 & 65.3 & 26.5 & 28.5 & 6.8 & 6.8 & 61.3 & 55.4 \\
\hline SD & 5.9 & 5.7 & 2.8 & 3.9 & 3.3 & 2.4 & 28.5 & 17.7 \\
\hline P value & $p=0.363$ & & $p=0.396$ & & $p=0.549$ & & $p=0.549$ \\
\hline
\end{tabular}

Rocco stitch was performed in all patients. The anastomosis was performed by two V-loc stitches, the ends of which were tied. Antibiotic prophylaxis was provided by a single dose of potent aminopenicillin as recommended by the antibiotic centre $(\mathrm{n}=98)$; fluoroquinolone was administered in patients with an allergy to aminopenicillin $(n=2)$. During the procedure, the urinary tract opening time (from bladder opening to completion of urethro-vesical anastomosis), console time, amount of fluid in the suction system, and the weight of prostate were monitored.

The prophylactic dose of low molecular weight heparin (LMWH) was administered to every patient for minimum of 7 days, starting the day before the procedure.

Evaluating perioperative blood loss in RARP has several difficulties. The amount of aspirated fluid during the procedure is further distorted by the lymphatic secretions of the traumatized tissue, irrigation fluid and the production of urine in the open urinary tract. The volume of intravenous infusions was recorded. Due to an inability to accurately measure actual diuresis, hourly diuresis was determined arbitrarily for all patients at $50 \mathrm{ml}$ per hour. The amount of urine produced was calculated based on the urinary tract opening time. The measurement of the suction fluid volume was done with an accuracy of $25 \mathrm{ml}$ after aspiration of all residual irrigation fluid from reservoir at the end of the procedure. The amount of urine and irrigation fluid $(500 \mathrm{ml})$ was subtracted from the amount of fluid in the suction capsule to estimate perioperative blood loss.

During the operation, we recorded console time, which represented the activity of the console surgeon from the connection of the robotic system to its disconnection. During this period, the urinary tract opening time was recorded from the opening of the bladder neck to the completion of the urethro-vesical anastomosis.

We assumed that the results would be significantly affected by the weight of the prostate. A larger prostate could mean longer operating time and greater blood loss. Therefore, all results were weighted for the grams of prostatic tissue.

Another factor that could have significantly affected the results was the patient's body mass index (BMI). Patients with higher BMI usually tend to not tolerate the Trendelenburg position as well as those with a lower BMI, a position that is essential for a good overview of the operating field. Obesity of the patients worsens the overview and increases the tendency for lymphorrhagia. BMI > 30 is also risk factor for thromboembolism.

The blood count was taken before the procedure, 3 hours after the procedure and the next day at $6 \mathrm{a} . \mathrm{m}$. The drainage fluid was monitored on postoperative day 1 POD 1 and 2 and the total number of blood transfusions was recorded. A permanent urinary catheter was extracted on POD7. Intraabdominal drain was extracted on the POD (postoperative day) 1 or 2 if there were no complications. Only three patients had urinary leakage of the anastomosis, detected initially biochemically (creatinine level over $500 \mu \mathrm{mol} / \mathrm{l}$ ) in drain and subsequently cystographically. In another two patients, increased lymphatic secretion from the drain was found. These patients were excluded from the evaluation of postoperative blood loss $(n=5)$.

Upon completion in 100 patients, the cases were unblinded and statistical processing performed, using NCSS statistical software (NCSS, Kaysville, UT, USA).

\section{RESULTS}

The characteristics of the treatment and control groups were not significantly different. Differences between age and PSA were assessed by the nonparametric Mann-Whitney U test. BMI and specimen weight were compared by the Kolmogorov-Smirnov test (Table 1).

No difference was found between the two groups in the volume of infusions during the procedure (Table 2).

No difference was found between the two groups in perioperative blood loss and perioperative blood loss related to gram of operated prostate (Table 3).

Blood count before the procedure was taken by patients' general practitioner which might have biased the

Tab. 2 Perioperative crystaloid infusions (ml).

\begin{tabular}{|l|l|l|}
\hline & TA & Placebo \\
\hline Average & 1825 & 1770 \\
\hline SD & 751 & 603 \\
\hline P-value & $p=0.656$ & \\
\hline
\end{tabular}

Tab. 3 Perioperative blood loss.

\begin{tabular}{|l|l|l|l|l|}
\hline \multirow{2}{*}{} & \multicolumn{2}{|l|}{ Overall blood loss $(\mathrm{ml})$} & \multicolumn{2}{l|}{ Blood loss per gram $(\mathrm{ml} / \mathrm{g})$} \\
\cline { 2 - 5 } & TA & Placebo & TA & Placebo \\
\hline Q1 & 93.0 & 97 & 1.99 & 1.94 \\
\hline Q2 & 222.5 & 212 & 3.58 & 3.92 \\
\hline Q3 & 377.5 & 386 & 6.61 & 7.80 \\
\hline P-value & $\mathrm{P}=0.712$ & & $\mathrm{p}=0.480$ & \\
\hline
\end{tabular}


results. Three patients were not analyzed because the haemoglobin level was higher after the procedure then before ( $\mathrm{n}=2$ from treatment group, $\mathrm{n}=1$ from control group). No significant difference was found in the absolute numbers for the haemoglobin decrease in 3 hours ( $3 \mathrm{hr} \mathrm{Hb}$-drop) and the day after surgery ( $24 \mathrm{hr} \mathrm{Hb}$-drop). Depending on the decrease in haemoglobin relative to gram of operated prostate, differences became significant (3hr Hb-drop/g and $24 \mathrm{hr} \mathrm{Hb}$-drop/g) (Table 4). The most striking differences between the groups were observed in patients with the DVC treated at the beginning of the procedure (Table 5).

In contrast, there were no significant differences between both groups if DVC was treated at the end of the procedure (Table 6).

Patients with biochemically and cystographically proven urinary leakage of anastomosis $(n=2$ in treatment group, and $\mathrm{n}=1$ in control group) and patients with extensive lymphatic secretion ( $\mathrm{n}=2$ in control group) were excluded from the evaluation of drainage. A significant difference was found between the study and control groups in overall postoperative drainage volume and overall postoperative drainage volume weighted for grams of prostate (Table 7).

No significant differences in console time were found between the study and control groups. Effects of definitive histology findings worsening (up-staging and upgrading) (Table 8,9$)$ or operating procedure variations on console time have also not been demonstrated. The only factor that significantly influenced console time was the patient's BMI (Table 10).

We did not observe significant reduction in incidence of positive surgical margins in group with tranexamic acid.

All patients were followed for 3 months after the procedure. Postoperative complications were recorded and graded based on severity according to the Clavien-Dindo definition (29). Only one episode of brachial artery

Tab. 4 Hemoglobin level drop overall.

\begin{tabular}{|c|c|c|c|c|c|c|c|c|c|c|}
\hline & \multicolumn{2}{|c|}{ Initial Hb level (g/l) } & \multicolumn{2}{|c|}{ 3hr Hb-drop (g/l) } & \multicolumn{2}{|c|}{ 3hr Hb-drop / g (g/l/g) } & \multicolumn{2}{|c|}{ 24hr Hb-drop (g/l) } & \multicolumn{2}{|c|}{ 24hr Hb-drop / g (g/l/g) } \\
\hline & TA & Placebo & TA & Placebo & TA & Placebo & TA & Placebo & TA & Placebo \\
\hline & $(n=48)$ & $(n=49)$ & $(n=48)$ & $(n=49)$ & $(n=48)$ & $(n=49)$ & $(n=48)$ & $(n=49)$ & $(n=48)$ & $(n=49)$ \\
\hline Average & 149.5 & 151.6 & 15.1 & 16.7 & 0.30 & 0.32 & 22.5 & 24.3 & 0.44 & 0.47 \\
\hline SD & 7.7 & 8.3 & 8.4 & 6.8 & 0.22 & 0.13 & 10.3 & 8.1 & 0.28 & 0.20 \\
\hline Q1 & 144.0 & 148.0 & 10.0 & 13.0 & 0.15 & 0.24 & 16.5 & 19.0 & 0.20 & 0.31 \\
\hline Q3 & 154.0 & 158.0 & 20.0 & 22.0 & 0.43 & 0.41 & 28.0 & 30.0 & 0.52 & 0.62 \\
\hline P-value & & & \multicolumn{2}{|l|}{$p=0.190$} & \multicolumn{2}{|l|}{$p=0.013$} & \multicolumn{2}{|l|}{$p=0.154$} & \multicolumn{2}{|l|}{$p=0.096$} \\
\hline
\end{tabular}

Tab. 5 Hemoglobin level drop in patients with DVC suturing at the beginning of procedure.

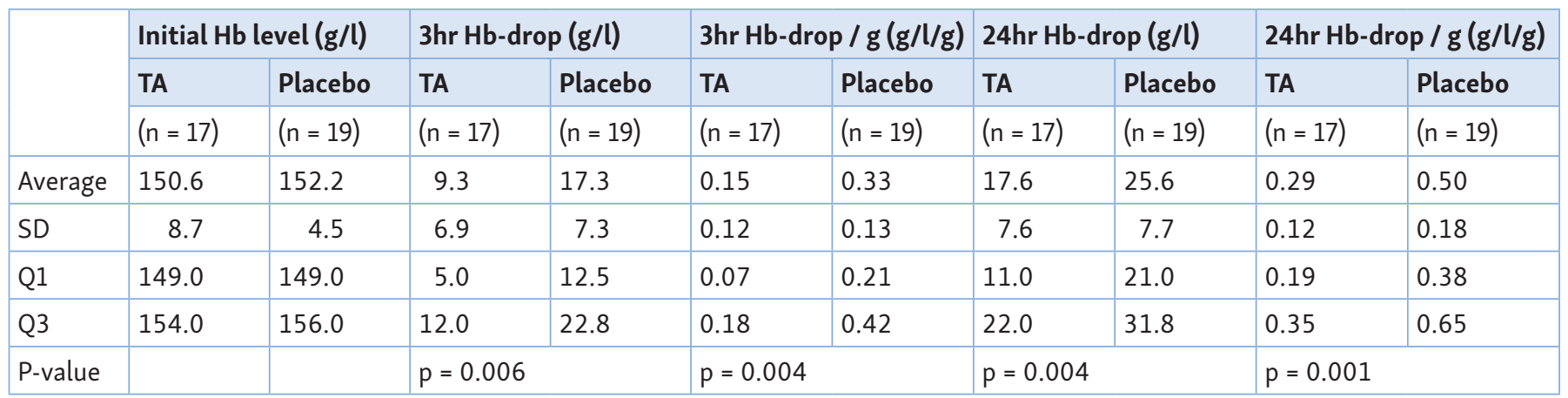

Tab. 6 Hemoglobin level drop Hemoglobin without DVC suturing at the beginning of procedure.

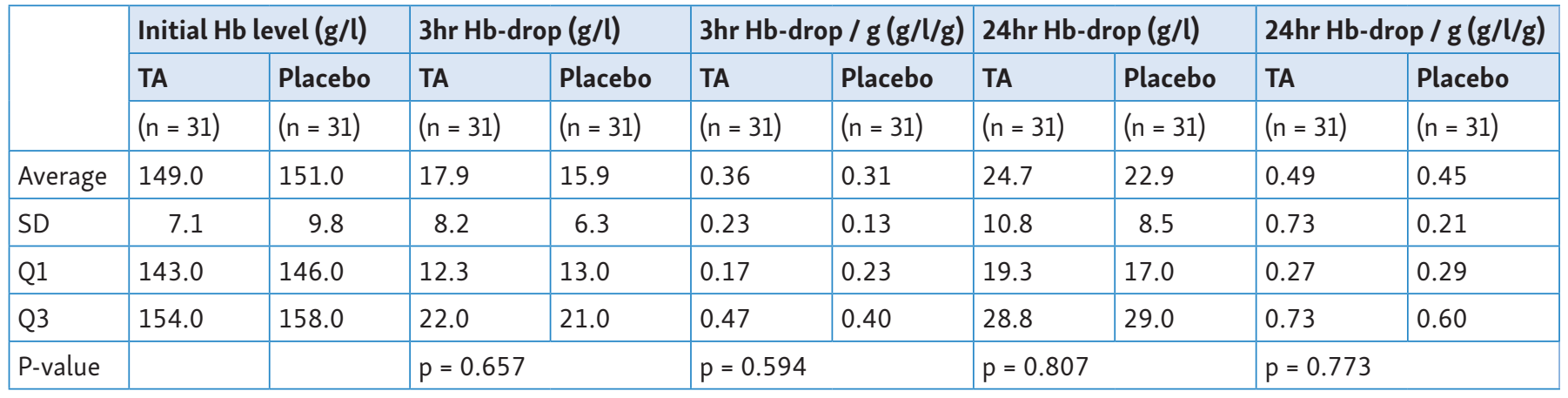


Tab. 7 Overall volume in drain.

\begin{tabular}{|l|c|l|l|l|}
\hline \multirow{2}{*}{} & \multicolumn{2}{|l|}{ Drain volume $(\mathrm{ml})$} & \multicolumn{2}{l|}{ Drain volume $/ \mathrm{g}(\mathrm{ml} / \mathrm{g})$} \\
\cline { 2 - 5 } & TA & Placebo & TA & Placebo \\
\cline { 2 - 5 } & $(\mathrm{n}=48)$ & $(\mathrm{n}=47)$ & $(\mathrm{n}=48)$ & $(\mathrm{n}=47)$ \\
\hline Q1 & 6.25 & 50 & 0.12 & 0.75 \\
\hline Q2 & 50 & 80 & 0.81 & 1.37 \\
\hline Q3 & 100 & 100 & 2.03 & 2.50 \\
\hline P-value & $\mathrm{p}=0.048$ & & $\mathrm{p}=0.023$ & \\
\hline
\end{tabular}

Tab. 8 Gleason score (GS) incidence.

\begin{tabular}{|l|l|l|l|l|}
\hline \multirow{3}{*}{ GS } & \multicolumn{2}{|l}{ Initial } & \multicolumn{3}{l|}{ Definitive } \\
\cline { 2 - 5 } & TA & Placebo & TA & Placebo \\
\hline 6 & 34 & 29 & 11 & 8 \\
\hline $7 \mathrm{a}$ & 13 & 15 & 24 & 30 \\
\hline $7 \mathrm{~b}$ & 2 & 4 & 9 & 6 \\
\hline 8 & 1 & 1 & 5 & 3 \\
\hline 9 & 0 & 1 & 1 & 2 \\
\hline
\end{tabular}

Tab. 9 Prognostic factor worsening.

\begin{tabular}{|l|l|l|}
\hline & TA & Placebo \\
\hline Up-grading & 32 & 26 \\
\hline Up-staging & 12 & 5 \\
\hline Positive surgical margin (PSM) & 11 & 14 \\
\hline
\end{tabular}

thrombosis was recorded in a patient in the control group (Dindo/Clavien II). The patients receiving tranexamic acid did not experience any complications in terms of stroke, acute myocardial infarction, or thromboembolic disease.

Two cases of significant postoperative bleeding were noted. One patient in the control group had an approximately $500 \mathrm{ml}$ hematoma in the pelvis, which was conservatively controlled, with no transfusion (Dindo/Clavien II). Another patient from the treatment group underwent acute laparoscopic revision for incipient haemodynamic instability, demonstrated haemoperitoneum, and a significant decrease in the blood count. During the revision, a haemoperitoneum of $3000 \mathrm{ml}$ was aspirated, but the source of bleeding was not found. Four blood transfusions were given (Dindo/Clavien IVa). No further complications were noted.

Two patients (one from the study group and the other from the control group) had increased secretion from drains, requiring longer drainage without further consequences (Dindo/Clavien I). In three patients with cystographically proven urinary leakage (one from the study group and two from the control group), we left the urinary catheter in place for 14 days after the procedure. Subsequent cystography did not indicate leakage and the catheter was removed (Dindo/Clavien I). One patient in the control group was conservatively treated for prolonged paralytic ileus lasting more than 5 days (Dindo/Clavien II). One patient from the treatment group experienced intestinal lesion and stercoral peritonitis because of adhesiolysis after a previously complicated appendectomy. During revision, $15 \mathrm{~cm}$ of ileum was resected (Dindo/Clavien IVa). Three months after the procedure, the patient was completely healed, with PSA level was $<0.008 \mathrm{ng} / \mathrm{ml}$, and completely continent (Table 11).

\section{DISCUSSION}

Despite all efforts, RARP carries significant blood loss in some patients. Perioperative bleeding impairs the visibility of the operating field, therefore, increases the risk of further bleeding, furthermore, worsens oncological and functional outcomes.

Radical prostatectomy is associated with a higher risk of thromboembolism. Open radical prostatectomy has a considerably higher risk of thromboembolic events (1.0-15.7\%) compared to a robotic (0.2-3.7\%) and laparoscopic approach (0.4-6.0\%) (30). Administration of antifibrinolytics, which potentially increase the risk of thromboembolism in laparoscopic surgery for pelvic malignancy, may rise certain doubts. However, our study, in agreement with recent meta-analysis of 11 studies involving 1177 patients with malignancy, did not find increased risk of thromboembolism following treatment with tranexamic acid (26).

Despite all our efforts, we have not been able to eliminate all potential study bias. The determined level of diuresis may not reflect the reality accurately. Administration of infusions during the procedure was not standardized,

Tab. 10 Impact on console time (minutes).

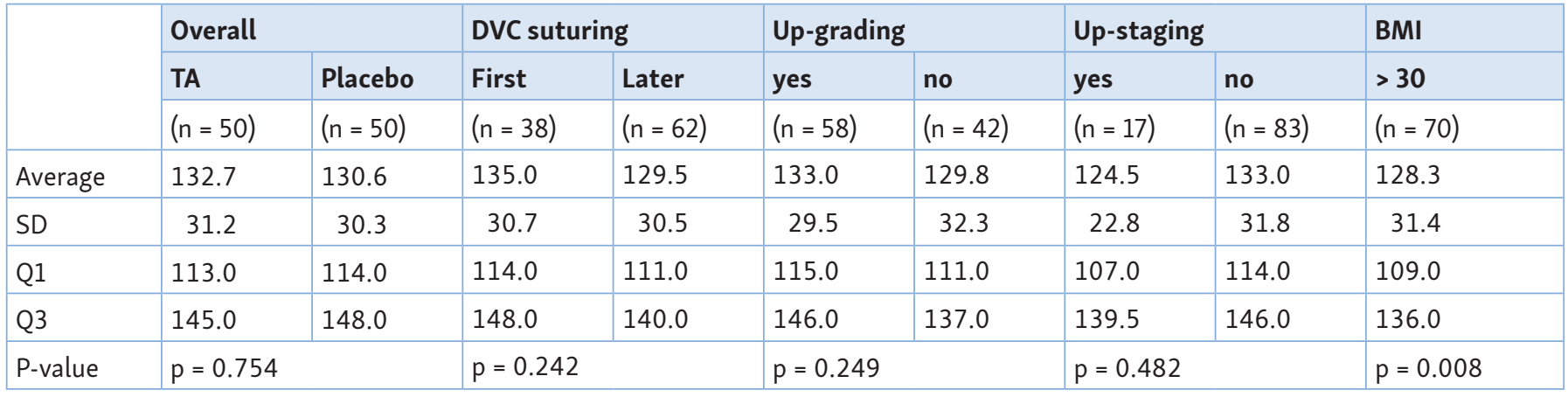


Tab. 11 Dindo/Clavien classification.

\begin{tabular}{|l|l|l|}
\hline Grade & TA & Placebo \\
\hline I & $\begin{array}{l}\text { 2 (prolonged lymphatic } \\
\text { secretion, urinary } \\
\text { leakage) }\end{array}$ & $\begin{array}{l}3 \text { (prolonged lymphatic } \\
\text { secretion, urinary } \\
\text { leakage }-2 \times \text { ) }\end{array}$ \\
\hline II & 0 & $\begin{array}{l}3 \text { (brachial artery thrombo- } \\
\text { sis, hematoma in the pelvis, } \\
\text { prolonged paralytic ileus) }\end{array}$ \\
\hline III & 0 & 0 \\
\hline IV & $\begin{array}{l}\text { 2 (laparoscopic revision } \\
\text { for haemoperitoneum, } \\
\text { intestinal lesion) }\end{array}$ & 0 \\
\hline V & 0 & 0 \\
\hline
\end{tabular}

but no statistically significant difference in the infusions between both groups was observed.

In addition, various degrees of tissue trauma were observed among the patients (e.g., adhesions of bowel, tissue fattening, prostate size, etc.) and, therefore, various lymphatic secretions were observed during and after the procedure.

We found the difference in postoperative drainage volume statistically significant, but it did not bring any clinical consequences. The drain was removed on the POD 1 or 2 with no difference between both groups.

Operations were performed by four surgeons, all of them with enough experience but with slightly different technique. Three of the surgeons performed DVC treatment after prostate removal using several turns of the barbed suture, and one surgeon after opening the endopelvic fascia with two loops of PDS stitch at the beginning of the procedure. We confirmed that ambiguous overall results were affected by mixing the two variants of the surgical procedure. There were no significant differences between both groups if DVC was treated at the end of the procedure.

Significantly lower postoperative losses in the latter case can be explained by the greater stability of the thrombus produced by the early suturing of the DVC, potentiated by the action of the tranexamic acid.

The effect of tranexamic acid on the incidence of positive surgical margins is not clear from this pilot study and will be analyzed in following study.

\section{CONCLUSION}

Prophylactic use of tranexamic acid at the beginning of the procedure in urology, in contrast to neurosurgery, orthopaedics or cardiac surgery, is not common.

In our pilot study we demonstrated the safety of $10-20 \mathrm{mg} / \mathrm{kg}$ of tranexamic acid at the beginning of RARP. No patient from the treatment group developed a thromboembolic event within 3 months after the procedure. In addition, we showed that administration of tranexamic acid at the beginning RARP significantly reduces the decrease in haemoglobin after the procedure, when treating the DVC at the beginning of the procedure. The results will be verified in following study in a larger patient population.

\section{ACKNOWLEDGEMENTS}

The work was supported by MH CZ - DRO (UHHK, 00179906).

The authors thank to RNDr. Eva Čermáková and Mgr. Iva Selke Krulichová, Ph.D. for the help with statistical analysis.

\section{CONFLICT OF INTEREST STATEMENT}

The authors declare no conflict of interest.

\section{REFERENCES}

1. Heidenreich A, Bastian PJ, Bellmunt J, et al. EAU guidelines on prostate cancer. part 1: screening, diagnosis, and local treatment with curative intent-update 2013. Eur Urol 2014; 65(1): 124-37.

2. Mottet N, Bellmunt J, Bolla M, Briers E, et al. EAU-ESTRO-SIOG Guidelines on Prostate Cancer. Part 1: Screening, Diagnosis, and Local Treatment with Curative Intent. Eur Urol 2017; 71(4): 618-29.

3. Nilsson S, Norlen BJ, Widmark A. A systematic overview of radiation therapy effects in prostate cancer. Acta Oncol 2004; 43(4): 316-81.

4. Barry MJ, Gallagher PM, Skinner JS, Fowler FJ, Jr. Adverse effects of robotic-assisted laparoscopic versus open retropubic radical prostatectomy among a nationwide random sample of medicare-age men. J Clin Oncol 2012; 30(5): 513-8.

5. Gandaglia G, Sammon JD, Chang SL, et al. Comparative effectiveness of robot-assisted and open radical prostatectomy in the postdissemination era. J Clin Oncol 2014; 32(14): 1419-26.

6. Kasabwala K, Patel NA, Hu JC. Review of optimal techniques for robotic-assisted radical prostatectomy. Curr Opin Urol 2018; 28(2): 102-7.

7. Montorsi F, Wilson TG, Rosen RC, et al. Best practices in robot-assisted radical prostatectomy: recommendations of the Pasadena Consensus Panel. Eur Urol 2012; 62(3): 368-81.

8. Sammon JD, Karakiewicz PI, Sun M, et al. Robot-assisted versus open radical prostatectomy: the differential effect of regionalization, procedure volume and operative approach. J Urol 2013; 189(4): 1289-94.

9. Lee SJ, Seo H, Kim HC, et al. Effect of Intraoperative Red Blood Cell Transfusion on Postoperative Complications After Open Radical Cystectomy: Old Versus Fresh Stored Blood. Clin Genitourin Cancer 2015; 13(6): 581-7.

10. Linder BJ, Frank I, Cheville JC, et al. The impact of perioperative blood transfusion on cancer recurrence and survival following radical cystectomy. Eur Urol 2013; 63(5): 839-45.

11. Wang YL, Jiang B, Yin FF, et al. Perioperative Blood Transfusion Promotes Worse Outcomes of Bladder Cancer after Radical Cystectomy: A Systematic Review and Meta-Analysis. PLoS One 2015; 10(6): e0130122.

12. Dunn CJ, Goa KL. Tranexamic acid: a review of its use in surgery and other indications. Drugs 1999; 57(6): 1005-32.

13. Erstad BL. Systemic hemostatic medications for reducing surgical blood loss. Ann Pharmacother 2001; 35(7-8): 925-34.

14. McCormack PL. Tranexamic acid: a review of its use in the treatment of hyperfibrinolysis. Drugs 2012; 72(5): 585-617.

15. Benoni G, Lethagen S, Nilsson P, Fredin H. Tranexamic acid, given at the end of the operation, does not reduce postoperative blood loss in hip arthroplasty. Acta Orthop Scand 2000; 71(3): 250-4.

16. Nielsen JD, Gram J, Fabrin K, Holm-Nielsen A, Jespersen J. Lack of correlation between blood fibrinolysis and the immediate or post-operative blood loss in transurethral resection of the prostate. BrJ Urol 1997; 80(1): 105-10.

17. Sharifi R, Lee M, Ray P, Millner SN, Dupont PF. Safety and efficacy of intravesical aminocaproic acid for bleeding after transurethral resection of prostate. Urology 1986; 27(3): 214-9.

18. Casati V, Guzzon D, Oppizzi M, et al. Hemostatic effects of aprotinin, tranexamic acid and epsilon-aminocaproic acid in primary cardiac surgery. Ann Thorac Surg 1999; 68(6): 2252-6; discussion 6-7.

19. Claeys MA, Vermeersch N, Haentjens P. Reduction of blood loss with tranexamic acid in primary total hip replacement surgery. Acta Chir Belg 2007; 107(4): 397-401.

20. Fergusson DA, Hebert PC, Mazer CD, Fremes S, MacAdams C, Murkin JM, et al. A comparison of aprotinin and lysine analogues in high-risk cardiac surgery. N Engl J Med 2008; 358(22): 2319-31. 
21. Jendoubi A, Malouch A, Bouzouita A, et al. [Safety and efficacy of intravenous tranexamic acid in endoscopic transurethral resections in urology: Prospective randomized trial]. Prog Urol 2017; 27(16): 1036-42.

22. Kumsar S, Dirim A, Toksoz S, Saglam HS, Adsan O. Tranexamic acid decreases blood loss during transurethral resection of the prostate (TUR-P). Cent European J Urol 2011; 64(3): 156-8.

23. Pourfakhr P, Gatavi E, Gooran S, et al. Local Administration of Tranexamic Acid During Prostatectomy Surgery: Effects on Reducing the Amount of Bleeding. Nephrourol Mon 2016; 8(6): e40409.

24. Rannikko A, Petas A, Taari K. Tranexamic acid in control of primary hemorrhage during transurethral prostatectomy. Urology 2004; 64(5): 955-8.

25. Zaid HB, Yang DY, Tollefson MK, et al. Efficacy and Safety of Intraoperative Tranexamic Acid Infusion for Reducing Blood Transfusion During Open Radical Cystectomy. Urology 2016; 92: 57-62.
26. Montroy J, Fergusson NA, Hutton B, et al. The Safety and Efficacy of Lysine Analogues in Cancer Patients: A Systematic Review and Meta-Analysis. Transfus Med Rev 2017; 31(3): 141-8

27. Breau RH, Kokolo MB, Punjani N, et al. The effects of lysine analogs during pelvic surgery: a systematic review and meta-analysis. Transfus Med Rev 2014; 28(3): 145-55.

28. Wright JD, Ananth CV, Lewin SN, et al. Patterns of use of hemostatic agents in patients undergoing major surgery. J Surg Res 2014; 186(1): 458-66.

29. Dindo D, Demartines N, Clavien PA. Classification of surgical complications: a new proposal with evaluation in a cohort of 6336 patients and results of a survey. Ann Surg 2004; 240(2): 205-13.

30. Tikkinen KAO, Craigie S, Agarwal A, et al. Procedure-specific Risks of Thrombosis and Bleeding in Urological Cancer Surgery: Systematic Review and Meta-analysis. Eur Urol 2018; 73(2): 242-51. 